\title{
Does Self-Control Moderate the Relationship between Social Influence and Savings Behavior among Small Business Owners?
}

\author{
Eva Mpaata $\left(D{ }^{1}{ }^{1}\right.$, Ernest Saina ${ }^{2}$, Naomi Koske ${ }^{3}$ \\ 1,2,3 Moi University School of Business and Economics, Kenya.
}

\begin{abstract}
This study examined whether self-control moderates the association linking social influence to saving behavior among small business owners. Using a standardized questionnaire, the study utilized a crosssectional design to collect data from 402 micro and small business owners based in Kampala City. Process macro was used to analyze the interactive impact of self-control and social influence on saving behavior. The findings showed a significant interactive effect of selfcontrol and social influence on saving behavior in Kampala, Uganda. Also, the results showed that the social impact on micro and small business owners' saving actions, at any degree of self-control, has a significant impact. These findings provide the literature and theory in behavioral finance with valuable insights. The study employed a crosssectional design, rejecting a longitudinal analysis.

Furthermore, we focused on Kampala City, leaving out other Ugandan cities. For those with low self-control, the government can implement deliberate government policies that impose savings in national social security funds and scale up the percentage of social security system savings for all individuals with strong self-control. The study points to the moderating effect of self-control on the link between social influence and saving behavior.
\end{abstract}

凶empaata@mubs.ac.ug
ARTICLE INFO

Received: February 24, 2021

Revised: March 17 \& 27, 2021

Accepted: March 27, 2021

Published: April 14, 2021

Keywords:

Social Influence, Self-control, Saving Behavior

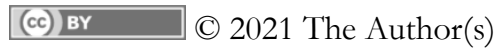

\section{Introduction}

In particular, savings behavior is essential for micro and small-business owners who experience inaccessibility to credit. Savings behavior plays a critical role in both economic growth and development. This is obvious, as small investments can be initiated over time by owners. This can only be achieved by planning and promoting saving. Saving behavior relates to the perception of saving choices, future needs, and behaviors that lead to wealth creation (Denton, Fretz, and Spencer (2011).

Consequently, savings are vehicles for economic growth, the potential drivers of which are individuals that find their savings to be essential to any economy(Khatun, 2018). Many MSEs do not flourish at all. This is 
due to numerous factors at the level of both the company and the owner. The owner's fundamental elements comprise; personal psychology, education, sex, and personal reasoning (Langevang, Namatovu, \& Dawa, 2012).

Africa usually has the lowest saving rates with the steady decline in the past three decades, according to Deaton (2005) and World Bank (2017), and this has adversely affected the slow-growing economies as the saving rates in Africa are perpetually poor (Elias \& Worku, 2015). Approximately 44\% of adolescents aged 17 to 25 and $11 \%$ of adults aged 40 to 55 are victims of consumptive behavior (Herawati, Candiasa, Yadnyana, \& Suharsono, 2018). Small and micro enterprises' sustainability is primarily affected by the individual management of their money. The same was claimed by Topa, Hernández, and Zappalà (2018), where the unpleasant actions of most Ugandan small business owners, such as poor saving conduct, financial indiscipline, lack of motivation and commitment to higher standards, negligence, carelessness, laziness, and lack of a dream, are the main factors deterring micro and small business survival and growth.

The saving behavior of an individual is understandable as part of the social environment of any society and should be adequate, thereby boosting the growth and development of the economy. Because of awareness gaps and behavioral biases, micro and small business owners often struggle to save, even though they have surpluses, resulting in the closure of most small businesses that contribute significantly to a country's GDP (Abebe, Tekle, \& ManoY, 2016). This collapse is evidenced by the annual business failure rate that currently stands between 30- 50 percent, attributable to the negative social network structure and the limited knowledge transfer of financial management matters among Micro and Small Enterprises (Kampumure, 2015). To accomplish the best saving action, it is essential to look at the social context in which individuals live. According to past studies, social influence is a significant direct predictor of saving behavior among Ugandan peoples (Homan, 2016). SI involves the impact of others' actions based on the social environment around them. Social influence includes a person or organization using social power to alter individuals' or groups' attitudes and activities in a particular direction (Franzoi, 2006).

Saving behavior is an extremely challenging step that requires one to be profoundly affected by their social interactions. Fang, Ng, Wang, and Hsu (2017), suggest that social impact encourages saving behavior, though the appropriate behavior is not inherently guaranteed. Also, Ky, Rugemintwari, and Sauviat (2018) noted that emerging economies are surrounded by unpredictable events such as health deterioration, death of a family member overwhelms and scares the few savings that would have accrued, hampering economic growth and development.

Also, the lack of savings contributes to welfare consequences, including low shock resistance and inadequate productive investment (Karlan, Ratan, \& Zinman, 2014). Moreover, most research focuses on cognitive factors affecting saving operations while ignoring non-cognitive like self-control which may influence the saving behavior of business owners. Also, most of the psychological factors have been taken in isolation when determining their influence on the saving actions of a person. Yet, human psychology is crucial to making either beneficial or regrettable choices if those choices are financial or non-financial(Strömbäck, Lind, Skagerlund, Västfjäll, \& Tinghög, 2017); Ningsih, Widiyanto, \& Sudarma, 2018).

Previous studies have shown that social impact affects people's saving actions (see; Jamal, Ramlan, Karim, and Osman (2015): Alwi, Amir Hashim, and Ali (2015). However, the moderating effect of self-control in the association between social influence and saving behavior has not yet been established. The majority of saving behavior research consisted primarily of direct social impact and self-control effects (Jamal et al., 2015); (Strömbäck et al., 2017). Therefore, it was essential to integrate both social influence and self-control variables into saving actions, hence the need to investigate whether self-control enhances or buffers the link of social influence to saving behavior.

Most people in Uganda rely primarily on their social networks/links for burial arrangements and religious practices that subsequently affect their saving power. On this basis, the primary purpose of the study was to analyze the moderating effect of self-control in the association between social influence and saving 
actions among micro and small business owners. Kampala City was chosen for this study because it is the Central Business District of Uganda with many micro and small enterprises and the city that attracts people from all walks of life looking for job opportunities from all regions of Uganda and across East Africa.

The article's subsequent parts include literature and theoretical perspective, methodology, findings and discussions, and conclusion. The article ends with policy implications and areas for further research.

\section{Literature Review}

\section{Social Cognitive Theory (SCT)}

The SCT is a highly influential and widely accepted theory in social psychology(Bandura, 2005). The approach has extended its scope to many fields, including behavioral finance. This theory emphasizes the ongoing mutual relationship between human behavioral factors and the environmental influence in understanding the mechanism of social cognitive learning (Bandura, 1989; Eun, 2019). This theory lies on the assumption that one learns by way of observing others. This is stipulated to occur in the immediate social context one resides that consists of families, friends, community, and mass media. Social cognitive theory is based on reciprocal causation of the triadic of intimate interactions, psychological and environmental forces that describe human nature. Bandura also explores the inherent ability of individuals that often influence human behavior, including: self-efficacy, expectations of performance, self-control, motivation, reactive management, and vicarious learning (Lown, Kim, Gutter, \& Hunt, 2015). This theory is more applicable in financial behavior, especially for micro and small business owners, since most participants learn from their families, peers, the community, society, and institutions about their financial behavior. The Social Cognitive Theory in this research focuses on all the study variables of social impact, self-control, and saving conduct. Social cognitive theory suggests that interfaces between the observations of other people, the environment, and one's cognitive abilities influence one's actions(Bandura, 1977; Mozahem, 2020)

The study's principal purposes were threefold. First, we sought to examine whether social influence predicts saving behavior. Secondly, it tested whether self-control would predict saving behavior and, lastly, evaluated the conditional effect of self-control in the link between saving behavior and social influence. Figure 1 , the analytical model of the analysis is illustrated.

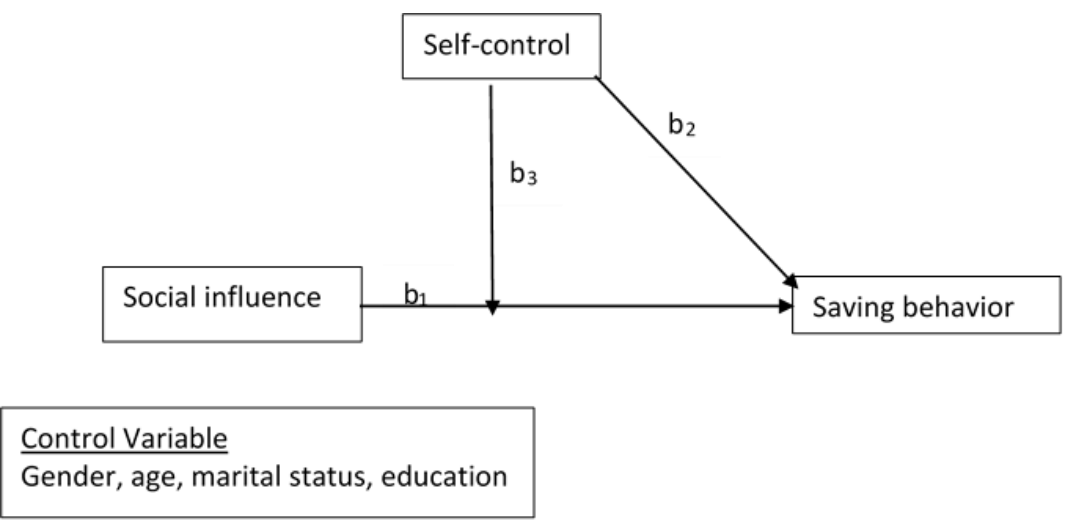

Figure 1 - Conceptual model. Source: Hayes (2018) Model 1.

The above conceptual model indicates that Social Intluence encompasses triends, families, community, and college. This affects a person's actions to save. Nevertheless, it is crucial to explore how self-control can moderate the relationship between social power and savings behavior.

\section{Social Influence on Saving Behavior}


Social influence has positive as well as negative impacts on people's behavior. This is because social influence allows both a group and an individual to attain a mutual or individual goal. Instead, the social effect may make sub-optimal decisions for individuals (Kast, Meier, \& Pomeranz, 2018). Past experiments have shown that Social Impact is successful at raising individual savings (Homan, 2016). This is achieved through strategies that include: target setting, regular follow-up to meetings, peer pressure from others, monitoring others' success, symbolic incentives for those who perform well, and guidance on how to achieve one's goal. SI includes the effect of actions of others based on the current social environment. Social control consists of a person or entity using social power to shift the nature or conduct of certain individuals in a specific path (Franzoi, 2006), as Noor Zaihan (2016) cited. A study by Mangleburg, Doney, and Bristol (2004) considers social influence as the degree to which family, friends, and colleagues influence the state of mind, perception, and behavior.

According to Hira (1997), family in general and specifically parents are the main relevant foundation of influence on financial behavior. According to Choi, Laibson, and Madrian (2011) monetary values are passed down by direct and indirect messages from parents to children. This in turn determines the kind of economic choices and performance they make in the future (Firmansyah 2014). Lyons (2007) also noted that almost 68 percent of people reported having received parents' financial information. Bowen (2002) further indicates that teenagers and parents have a significant association with understanding money. Social influence entails an individual or organization using social force to alter specific individuals or groups' disposition or actions in a defined way (Franzoi, 2006). Kinds of literature have shown that parents contribute to children's financial socialization, whereby, parents are influential in determining their children's financial actions (Sam, Geetha, \& Mohidin, 2012). Webley and Nyhus (2006) indicate that their economic socialization determines children's future orientation.

It is more likely that children who have a strong family relationship are future-oriented and have good financial conduct. Parent's position is significantly greater than that of the job experience of young adults and financial education in high schools (Shim, Barber, Card, Xiao, and Serido (2010). A set of parent and family support social support is essential in encouraging young adults to pursue their productive lives. Parents are financial role models by displaying positive financial actions before their children.

Savings assessments are dynamic and require significant economic expertise and experience on the part of individuals. Therefore, this could be the case for parents with a certain degree of financial literacy to teach their offspring specific skills to provide them with future financial management skills. This can result in children and young adults establishing their parent's financial attitudes. Childhood saving operations will impact their financial activities in the future by having consequences for their adult saving operations (Brown \& Taylor, 2016).

Norvilitis and MacLean (2010) reported that parents are inspired by realistic approaches to educating their children on money management, incentives, and bank accounts to minimize their use of credit cards at college. The researchers also noted that, during adulthood, adolescence is the most critical time that will affect the actions and attitudes of individuals. Parents thus play a significant role in influencing children in managing their financial affairs. In addition to parental variables, peer impact may also predict financial actions for individuals. Duflo and Saez (2002) discovered that people with equal interests tend to belong to the same way of life and establish links between the group and individual actions.

Bucciol and Veronesi (2014) also indicate that informal education from parents is impactful compared to formal education at colleges, as parents exhibit various activities that depend on different socio-demographic variables. System of parental teaching decides the potential to solve financial challenges in the future, and it is more successful, particularly when various teaching methods are merged. Teaching how to save during childhood and adolescence is the most effective approach.

Similarly, Jamal et al. (2015) showed that colleagues' impact has a critical role in choosing the saving capacity of a person. Parents who exhibit good financial behavior before their children develop their children's 
saving behavior through socialization (Noor Zaihan (2016). Jamal et al. (2015) said that individual financial conduct could also be influenced by peer influence. Alwi et al. (2015) asserted that when making decisions, people are affected by peer pressure. In reality, Laible, Carlo, and Roesch (2004) said that people's behavior is learned through direct and indirect contact with their mates. Dangol and Maharjan (2018)argue that peers and parents remain potent agents of socialization that decide the behavior of adolescents in the future. Many teenage desires are derived from wants rather than financial needs. Yet, they are expected to imitate what their parents do right from childhood, as those who talk to parents about financial problems have more vital abilities to meet financial needs. Thus, we hypothesize here:

$H_{1}$ : Social influence significantly and positively predicts saving behavior

\section{Self-Control and Saving Behavior}

G. J. Kim and Hanna (2017) investigated the relationship between self-control systems and saving actions. Results showed that having one or more saving laws had a positive effect on saving likely hood, a weak impact on retirement, and the saving goal of creating families. Noor Zaihan (2016) explored the effect of selfcontrol on saving actions; a positive and significant relationship was established. Rha, Montalto, and Hanna (2006) utilized data of the 1998 Consumer Finance Survey (SCF) to examine the influence of psychological factors, especially the role of self-control, on saving behavior and found a greater likelihood of saving for people who were motivated to save. The study revealed that individuals with saving rules are most likely to save than those without.

Achtziger, Hubert, Kenning, Raab, and Reisch (2015) indicates that individuals with low self-control are likely to indulge in regular shopping, on the other hand, Gathergood (2012) asserts that people with financial related self-control issues and are likely to suffer from credit withdrawals, and unforeseen sustainability costs leading to over-indebtedness. Biljanovska and Palligkinis (2018) found that, due to lack of planning, supervision, or engagement, households with self-control problems had poorer asset accumulation, while Choi et al. (2011) reported that individuals with less self-control are disadvantaged to acquire adequate capital. Personal financial management needs a priority and consistent lifestyle, that is, the self-awareness to follow the guidelines and respond to the changes that directly influence self-control. Sirine and Utami (2016) concluded that self-control influences the saving actions of people positively and significantly. Lee concluded that, compared to people who have never trained self-control, people who always train self-control have the best and more positive motivation and will save. Lim (2011) concludes that self-control has a significant impact on saving activities.

According to Biljanovska and Palligkinis (2018), wealth accumulation is lower for individuals with low self-control due to the absence of planning, supervision, or participation. Choi et al. (2011) found that retirement money is less likely to be saved for poor self-control persons. A person with high self-control can take care of his/her financial resources and better financial conduct. On unnecessary things and pointless events, they don't spend money. People with greater self-control are more likely to achieve their goals and be more successful in various areas of life (De Ridder, Lensvelt-Mulders, Finkenauer, Stok, \& Baumeister, 2012). Liu (2014) examined the Professional Financial Advice (PFA) and self-control effects on saving and concluded that the ability to self-control has a favorable and meaningful association with gross annual savings, financial assets, and emergency funds. This is why we hypothesize:

$\mathrm{H}_{2}$ : Self-control positively and significantly predicts saving behavior

\section{Social Influence and Saving Behavior: Moderating role of Self-Control}

Self-control is a self-regulation mechanism in the circumstances involving a simple trade-off between long-term goals and immediate pleasure (Bernheim, Ray, \& Yeltekin, 2015). J. H. Kim and Park (2015) described self-control as the degree to which the self-awareness of an individual has control over events and ongoing circumstances and represents the perception of their ability to deal with them. Self-control is intentional selfregulation, according to Vitell et al. (2009), which provides an individual with the capacity to act morally by 
overcoming one's inclination to behave poorly. Self-control can break resist temptations, bad habits and avoid urges (Fujita \& Han, 2009). J. H. Kim and Park (2015) agreed that for psychological adaptation, a sense of control is necessary, which is a more significant predictor of an individual's ability to perform actions by taking action to achieve the desired goals. As it offers a training ground for behavior, social impact is one of the critical factors associated with individual actions. This is achieved by modifying behaviors, motives, and rationalizations that facilitate a particular activity and thereby create opportunities for specific actions to be taken. Self-control also leads to actions beyond the influence of the family, meaning that self-control is an important facilitator in behavioral research.

As far as the moderating role is concerned, extensive research has used self-control as a moderator. For instance, a study by Mobarake, Juhari, Yaacob, and Esmaeili (2017) on the conditional effect of self-control in the association between adolescents' social influence and saving behavior in Tehran, Iran. This relationship was substantially moderated by self-control. Other studies have used self-control as a moderator (see; Nepomuceno and Laroche (2017). On this basis, as a moderator, self-control was used to determine the moderating effect in the association between social impact and saving behavior, thus hypothesizing: $H_{3}:$ Self-control significantly moderates the link between social influence and saving behavior

\section{Methodology}

\section{Design, Population, and Sample}

A cross-sectional design was employed because data were collected at one point in time. The analysis was correlation and explanatory as well as empirical in nature. The Uganda Bureau of Statistics (UBOS) registry reported a population of 51,225 registered MSEs in the Central Division of Kampala, 46,270 of which were registered in selected administrative units within the division. Using the 1967 formula of Taro Yamane, a sample of 430 respondents was generated. Of the 430 questionnaires, 405 were returned; three (3) were not fully completed and were eliminated from the study, leaving a total of 402 respondents who were used for further analysis. This resulted in a 93\% response rate, which, as suggested by most researchers to be appropriate as it is above the 50\% threshold. The survey formula of Neyman stratum allocation was used to assign the respondents to the respective administrative units in Kampala.

To obtain an adequate study sample, the researcher used multi-stage sampling to create clusters and sub-groups until the researcher achieved the desired sample size. Utilizing an updated business register from the Uganda Bureau of Statistics (UBOS), the researcher initially geographically clustered MSEs basing on their location in the selected administrative units within the Kampala Central division. This was reasonable given the different organizational units' location, the heterogeneity of the MSEs in the chosen executive departments, and the respondents' discrepancies. The choice of the administrative unit is based on the intensity of the economic activity of MSEs. For this research, the unit of analysis was the micro and small businesses, while the business owners were the unit of inquiry.

\section{Instrument and Sampling}

A close-ended self-managed questionnaire was employed to collect responses from the micro and small business owners. A pilot study was performed in Eldoret, Kenya, among 41 micro and small business owners. This is one of the country's central business districts with various micro and small enterprises. The results showed that, as recommended by (Taber 2018), all the variables under analysis had alpha coefficient reliability above 0.60. Saving conduct had an alpha coefficient of .813 with seven retained items. Social impact with 8 retained items had an alpha coefficient of .691. Eventually, self-control with nine retained items had an alpha coefficient of .658. 
Descriptive results from the sample selected for the research showed that $55.7 \%$ were male, while $44.3 \%$ were female. The results also showed that most of the respondents were between 31 and 35 years of age $(\mathrm{N}=$ 154) with 38.3 percent, and the least were those between 15 and 20 years of age $(\mathrm{N}=2)$, representing .5 percent. Moreover, demographic statistics further reveal that 296 respondents (73.6 percent) were married, and only 6 lost their spouses (1.5 percent). Education results found that the majority (180) had attained secondary education (44.8 percent), while only (7) had attained postgraduate education (1.7 percent). The majority of the respondents were sole proprietors; 190 (47.3 percent) and just 9 (2.2 percent) were those of other businesses. Lastly, the majority $(\mathrm{N}=182), 45.3 \%$ of the respondents, earned income $(400,001-700,000)$, while the least that earned below 200,000 Ugx were only $\mathrm{N}=8(2 \%)$.

\section{Measurements of Study Variables}

Saving behavior was measured using previous scholars' items adopted and modified by; Chowa and Despard (2014), Dangol and Maharjan (2018), (Ariffin, Sulong, \& Abdullah, 2017), who recommended them as accurate and relevant for studies of financial behavior. Social influence measures were adopted and modified from previous scholars such as (Dangol \& Maharjan, 2018), (Hanachi, 2005), (Dinc \& Budic, 2016), (J. Kim, Eys, Robertson-Wilson, Dunn, \& Rellinger, 2019). Furthermore, self-control used measurement items adopted and updated by (Lindner, Nagy, \& Retelsdorf, 2015); (Strömbäck et al., 2017) and (Ariffin et al., 2017), as they were found to be accurate and valid. All items were anchored on a 7-point Likert scale.

\section{Results and Discussion}

\section{Preliminary Assessments}

The results in table1 show that saving behavior had the highest mean of 6.021 and .7275 standard deviation; on the other hand, self-control had the lowest mean and standard deviation of 5.4303 and 1.5614, respectively. Correlation findings indicate that both factors were strongly correlated with saving behavior with the strongest association of social influence with $\mathrm{r}=.651, \mathrm{p}=.000 ; \mathrm{p}<.01$ and self-control with $\mathrm{r}=.615$, $\mathrm{p}=.000 ; \mathrm{p}<.01$.

Table 1: Mean, Standard deviation, Reliability, and Correlation

\begin{tabular}{lcrlll}
\hline Variable $(\mathrm{N}=402)$ & $\mathrm{M}$ & $\mathrm{SD}(\sigma)$ & Reliability $((\alpha)$ & 1 & 2 \\
\hline Saving behavior (1) & 6.021 & .7275 & .813 & $.651^{* *}$ \\
Social influence (2) & 5.6819 & 1.2704 & .691 & $.615^{* *}$ & $.541^{* *}$ \\
Self- control (3) & 5.4303 & 1.5614 & .658 & & \\
**. Correlation is significant at the $\mathbf{0 . 0 1}$ level (2-tailed). & &
\end{tabular}

Factor analysis with varimax rotation was used to check on the construct validity of the instrument. KMO sampling adequacy test was used to determine sample adequacy for factorability. KMO values of less than .5 do not require factor analysis to be applied. Thirty questions related to the study variables were analyzed with Varimax rotation using the principal component analysis. Factor analysis findings for savings behavior showed that the results of factor loadings above 0.5 were preserved. Seven out of nine items loaded undersaving actions for additional review. Factor1 explained $33.344 \%$ of the total variance, while factor2 explained $22.438 \%$. The first and the second group of factors were named saving consistency and saving attitude, respectively. The Kaiser-Meyer - Olkin value (0.775) was above 0.5, suggesting that the sample used was sufficient. The Bartlett sphericity analysis was also significant. Table 2 shows the results reported above. 


\begin{tabular}{|c|c|c|}
\hline & 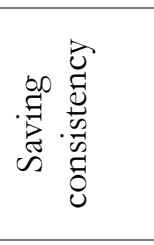 & 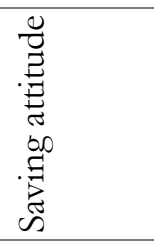 \\
\hline I permanently save a portion of my money when I get it. & .832 & \\
\hline I adhere to the plan I make on how to use my money. & .789 & \\
\hline To achieve specific goals, I save & .729 & \\
\hline Because it's a nice thing to do, I save & .559 & \\
\hline Before I buy something for myself, I first compare prices. & & .835 \\
\hline I pay maximum attention to the proportion of the money I save & & .624 \\
\hline I always consider whether there's a need before making any expenditure to save. & & .556 \\
\hline Eigen value & 2.334 & 1.571 \\
\hline Variance $(\%)$ & 33.344 & 22.438 \\
\hline Cumulative Variance $(\%)$ & 33.344 & 55.782 \\
\hline$K M O=.775$, Bartlett's test of sphericity $=621.669, d f=21$, sig $=.000$ & & \\
\hline
\end{tabular}

Extraction Method: Principal Component Analysis. Rotation Method: Varimax with Kaiser Normalization. Rotation converged in 5 iterations.

Social Influence factor analysis was conducted to ensure that the items used were accurate and consistent before further research. Factors of social impact, especially when it comes to money management, are/were a clear indicator for my parents; if I wanted to set money away, among others, my family would consent to such a decision. Just two items were not loaded out of ten items and were thus eliminated from further analysis. Factors one, two, and three were respectively named as peer influence, parent influence, and close family influence. These factors explained $22.999 \%, 20.997 \%$, and $17.356 \%$ respectively of the total variance. Also, the analysis output indicates a KMO of .64 above .5 as recommended. The Bartlett sphericity results indicate a $\chi^{2}$ of $902.271, \mathrm{df}=36$, and is significant at .000 .

Table 3: Factor Analysis of Social Influence

I feel under social pressure to set aside money for the future.

.734

I often get involved with people who are close to me in financial management practices. $\quad .671$

With my colleagues, I still compare the amount of savings and expenditures

Closest friends approve of whining I am doing what is important to me .605

If I decided to save, my colleagues would approve of that decision

I regularly manage my money because my parents taught me so since childhood $\quad .932$

My family members are an excellent example regarding financial management $\quad .929$

My relatives recommend me to save $\quad .831$

People who are valuable to me believe I can save $\quad .784$

$\begin{array}{lrrr}\text { Eigen value } & 2.07 & 1.89 & 1.562\end{array}$

$\begin{array}{llll}\text { Variance }(\%) & 22.999 & 20.997 & 17.356\end{array}$

Cumulative Variance (\%) $\quad 22.999 \quad 43.996 \quad 61.352$

$K M O=.641$, Bartlett's test of sphericity $=902.271, d f=36$, sig $=.000$ 


\section{Factor Analysis for Self-Control}

Self-control elements included resistance to the temptation to spend money and self-discipline in saving cash, among others. The item (SC7) was removed because it didn't load, leaving only nine items loaded. Three factors loaded under self-control accounting for $21.613 \%, 17.692 \%$, and $16.694 \%$ variance. Self-regulation, willpower, and foresight were respectively named as the factors. KMO measure exceeding 0.5 was used to measure sampling adequacy, and the Bartlett result was significant.

Table 4: Factor Analysis of Self-Control

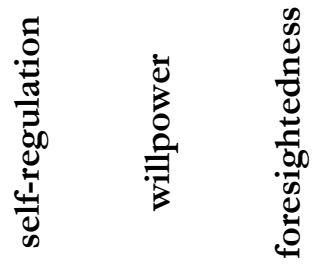

I always avoid spending extravagantly

I am more self-disciplined when it comes to spending money

When I have money, sometimes I regret my expenditures

When it comes to money, I focus on current needs than future needs

Occasionally, when am with the money, I keep spending on some things even when they are not suitable for me

It's tough for me to change my expenditure patterns

I don't concentrate at work when I have money

I mind of today than the future

I like to spend all my money immediately

Eigen value

Variance (\%)

Cumulative Variance (\%)
.749

.732

.651

.565

$K M O=.724$, Bartlett's test of sphericity $=518.453, d f=36$, sig $=.000$

\section{Testing for Moderation}

Table 5: Moderation Effect

\begin{tabular}{lcccccc}
\hline \multicolumn{1}{c}{$\mathrm{R}$} & $\mathrm{R}-\mathrm{SQ}$ & $\mathrm{MSE}$ & $\mathrm{F}$ & $\mathrm{df1}$ & $\mathrm{df2}$ & $\mathrm{P}$ \\
\hline \multicolumn{1}{c}{$\mathbf{. 7 3 2 5}$} & .5366 & .2496 & 65.1646 & 7.000 & 394.000 & 0.000 \\
& & & & & & \\
Constant & Coeff. & $\mathrm{Se}$ & $\mathrm{t}$ & $\mathrm{p}$ & $\mathrm{LLCI}$ & $\mathrm{ULCI}$ \\
Self-control & 2.5507 & .3856 & 6.6147 & .0000 & 1.7926 & 3.3089 \\
Social influence & .3336 & .0702 & 4.7493 & .0000 & .1955 & .4716 \\
Interaction term & .4046 & .0681 & 5.9397 & .0000 & .2707 & .5386 \\
Gender & -.0305 & .0128 & -2.3876 & .0174 & -.0555 & -.0054 \\
Age & -.0135 & .0519 & -.2594 & .7954 & -.1155 & .0886 \\
marital & .0374 & .0250 & 1.4951 & .1357 & -.0118 & .0866 \\
educ & .0431 & .0527 & .8179 & .4139 & -.0605 & .1467 \\
\end{tabular}


Table 6: Test of highest order Unconditional Interaction

\begin{tabular}{cccccc}
\hline & R-SQ & F & df1 & df2 & P \\
\hline Interaction term & .0067 & 5.7008 & 1.0000 & 394.000 & .0174 \\
\hline
\end{tabular}

Results from Table 5 indicate how self-control (shown as direction 'b1' in Figure 1) moderates the path from social impact to saving action. The model generated $.5366 \mathrm{R} 2$, indicating that $53.66 \%$ of the variance was accounted for. The model included control variables; the results suggest that all were negligible. The results also showed that social influence and self-control are important predictors of saving actions, with a coefficient of social impact. $=.4046, \mathrm{CI}=.2707, .5386$ and a coefficient of self-control $=.3336, \mathrm{CI}=.1955, .4716$. Thus accepting both hypothesis one and hypothesis two. Results further indicate a negative coefficient (-.0305), $p=.0174<0.05, \mathrm{CI}=(-.0555,-.0054)$ when it comes to the interaction.

Table 7: Moderating effect of Social Influence on Saving Behavior at values of the Moderator(s):

\begin{tabular}{lllllll}
\hline Self-Control & Effect & se & $\mathbf{t}$ & $\mathbf{p}$ & LLCI & ULCI \\
\hline 3.8689 & .2868 & .0277 & 10.3707 & .0000 & .2324 & .3412 \\
5.4303 & .2392 & .0241 & 9.9319 & .0000 & .1919 & .2866 \\
6.9918 & .1917 & .0345 & 5.5586 & .0000 & .1239 & .2595 \\
\hline
\end{tabular}

Source: Research data

From table 7 , the effect of social influence on saving behavior is significant at 0.0000 at whether low, moderate, or high levels of self-control. In contrast, at low self-control levels (3.8689), the conditional effect of social influence $(\mathrm{X})$ on saving behavior $(\mathrm{Y})$ is higher (.2868) than at higher levels of self-control (6.9918); the effect is low (.1917).

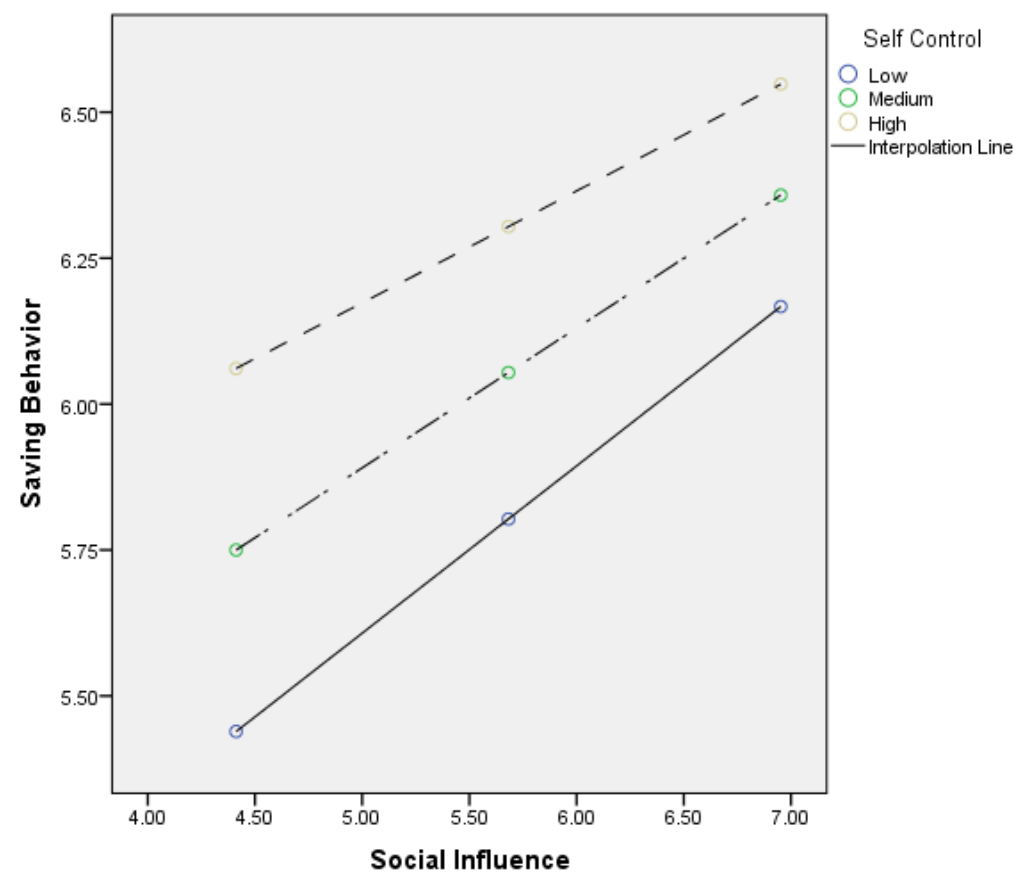

The above modgraph shows that at low self-control levels, the slope is steeper, suggesting that social influence on saving will be high than at higher self-control rates. The slope is less steep, meaning that the impact of social influence on saving behavior is low. 


\section{Discussion}

Study results show that social impact is a significant factor in saving conduct. This concurs with Jamal et al. (2015), whose findings show how family engagement plays a major role in fostering student savings actions. The same was claimed by Cronqvist and Siegel (2015), who discovered that parenting influences the variability in youth savings rates, with the effect diminishing over time. Social and family influences contribute to particular financial actions before kids are formally educated, so the social impact is more relevant and more effective than overall financial training (Batty, Collins, \& Odders-White, 2015). Furthermore, the nature of the results is consistent with the argument of Ningsih et al. (2018), where friends' views and preferences are factors that can determine the lifestyle of an individual, including the decision to save. Individuals with good self-regulation choose to regulate the use of money and aim to manage money properly by increasing their money-saving goal.

Furthermore, a study by (Lim 2011) aimed to investigate psychological factors (social impact) and the effect of self-control on saving actions. Their research found that parental impact favorably affects the right of individuals from childhood and therefore affects their self-control and later assists to save more. The study by (Achtziger et al., 2015); (Gathergood 2012) also found that compulsive spending is more likely for individuals with low self-reported self-control since they probably suffer from indebtedness due to uncontrollable expenditures.

By taking into account the social context in which individuals perform acts, SCT considers the unique way people learn and sustain actions. The social context consists of families, friends, community, and mass media that impose the social strain and societal expectations that a person may benefit from (Wills, Ainette, \& Walker, 2015). The theory suggests that the triad of intimate interactions, psychological and environmental forces that explain human nature. Environment factors reflect situations and an atmosphere where the action is performed, while impulses, desires, characteristics, and other specific driving forces are human factors. The theory emphasizes the mechanism of behavioral transformation, including self-efficacy, perceptions of performance, self-control, motivation, emotional regulation, and observational learning (Lown et al., 2015).

The study further defined the moderating role of self-control in the relationship between social power and saving actions. This is illustrated in table 5, showing the self-control interaction on the link between social influences and saving actions. There was a significant impact of the interaction $(\mathrm{p}=.0174<0.05)$, coeff. $=-.0305$, $\mathrm{CI}=-.0555,-.0054$. Hypothesis 3 is supported in this analysis as both confidence intervals have no zeros.

Table 7 reveals that the impact of social power on saving actions among micro and small business owners is high at low rates of self-control. Nevertheless, the effect of social impact on saving actions decreases as self-control rises. It may be because while one has a lot of self-control, one is less susceptible to social influence that may affect their saving actions. In contrast, one with less self-control is more vulnerable to social influence that impacts their behavior. Based on the results, we present a new perspective in the research field of behavioral finance are generated by the moderating impact of self on the ties between the variables used in the study.

\section{Conclusion}

This study shows that both psychological and sociological factors are key to determining behaviors between individuals both formally and informally towards savings to encourage financial inclusion of micro and small businesses. It further shows that the impact of social influence on saving behavior is significant across self-control levels, so self-control buffers the association of social influence and saving behavior. However, we suggest that external interference impacts more saving behaviors where one has low self-control. In the African sense, people live together and are thus strongly affected by their family and friends' social experiences, thus impairing their level of self-control. Because self-control is a self-manage mechanism that requires a trade-off between long-term goals and immediate gratification, its internal presence in an individual minimizes the 
influence of external pressure on an individual's reasonable course of action (Bernheim et al., 2015). By nurturing their self-control to maintain levels of social influence, this study may help individuals as they are selfaware of handling prevailing conditions and exhibit their ability to handle circumstances (J. H. Kim \& Park, 2015). Just as social capital is vital, if combined with a lack of self-control, too much of it will affect a person by bad choices, hence the need for self-control to minimize social pressure that can have detrimental effects on one's actions. This research is in conjunction with analysis by Martinsson, Myrseth, and Wollbrant (2014), in which people with self-control manage their finances better by spending less than those with no self-control.

\section{Theoretical and Practical Implications}

This research supports the Social Cognitive Theory (SCT), which postulates learning as a social text mechanism. The SCT suggests that the triad of interpersonal relationships, personal and environmental influences can explain human nature. Environmental influences represent conditions and an environment where behavior is performed, while human factors include impulses, preferences, traits, and other unique motivating powers. Self-efficacy, outcome goals, self-control, motivation, emotional regulation, and observational learning are some variables that could be involved in the behavioral adjustment process (Lown et al., 2015). The theory suggests that interpersonal, peer-reciprocal, socio-economic, and environmental influences are dependent on social learning (Chaulagain, 2019). The SCT determinants correspond to all variables of the study.

The research contributes to the current literature as it further reinforces what other studies have previously shown that social power and self-control directly affect people's saving actions. The study also provides some new insights that self-control can strengthen the connection between social influence and saving action. Third, the study refers to the social cognitive theory, where a person is expected to have a self-regulated capacity to push himself or herself to achieve specific results by determining and acting appropriately on his or her actions hence utilizing self-control moderators this study.

The findings of the report will aid in deliberate public policy. As self-control is an inbuilt trait and most individuals are indecisive, the Government should implement compulsory saving of money by deliberate saving schemes like the national social security fund. For those who are already saving, the government should scale up the saving, for instance, from 10 percent saving to 20 percent saving through the social security fund. Also, the research findings will help policymakers and practitioners devise strategies or services to improve human financial behaviors. Policy and financial practitioners need to implement policies that enhance self-control abilities in terms of practical outcomes like financial management and savings. Also, financial planning practitioners should inculcate self-control mechanisms among micro and small business managers and owners. Financial experts should promote budgeting when classified to help people develop self-control in financial management decisions (Liu, Yilmazer, Loibl, \& Montalto, 2019). The results of the research are particularly relevant for financial education strategists, where financial education requires not just the delivery of information on the effectiveness of specific financial conduct, but also the cognitive stimulation of individual skill concepts such as self-control amidst social interaction (Trzcińska, Sekścińska, \& Maison, 2018).

\section{Limitation and Future Direction}

We focused on a quantitative and cross-sectional design, and no attention has been paid to a longitudinal design. This creates an avenue for future researchers. We also recommend the mixed approach method to expose more challenges that affect people's savings actions. The geography scope of the study is another limitation. Thus the study can be replicated in other parts of the county and the world, as different findings could occur.

\section{Disclosure Statement}


The authors declare no conflict of interest. Furthermore, no other person except the authors has played a role in the design of the study, in data collection, analysis, or interpretation, in manuscript writing, or in the decision to publish the results.

\section{Ethical Approval}

The Uganda National Council for Science and Technology initially authorized the researcher to carry out work through a letter to access the micro and small businesses chosen. An introductory letter from Moi University, a copy of the questionnaire with a cover page explaining the benefits of the analysis, and expected outcomes

\section{Informed Consent}

The researcher adhered to the principles of research ethics, such as the regulation of informed consent. Participants decided to participate in the study and were free, if desired, to choose secrecy, confidentiality, anonymity, and accuracy. Participants in the study were provided with the intent, methodology, and duration of the study. Participants were granted full disclosure of the project scope, threats, benefits, and alternatives, including an extended ability to ask detailed questions about this study. The researcher maintained the protection of patent, copyright, and other forms of intellectual property. The study kept all information received by the researchers fully confidential. Honesty has been preserved in the research process, outcomes, methods, and procedures to discourage data fabrication, forgery, or misrepresentation. All quotations used and sources accessed by citations were specifically documented and acknowledged.

\section{Acknowledgments}

I thank Makerere University Business School Management and Moi University for the opportunity to pursue my Ph.D. studies. I thank my Supervisors, Dr. Naomy Koske and Dr. Ernest Saina, for their invaluable support and unwavering motivation during the development process of this research paper.

\section{References}

Abebe, G., Tekle, \& ManoY. (2016). Changing Saving and Investment Behavior: the Impact of Financial Literacy Training and Reminders on Micro-business CSAE Working Paper Series 2016-08. University of Oxford: Centre for the Study of African Economies.

Achtziger, A., Hubert, M., Kenning, P., Raab, G., \& Reisch, L. (2015). Debt out of control: The links between self-control, compulsive buying, and real debts. Journal of Economic Psychology,, 49, 141-149.

Alwi, S., Amir Hashim, I. Z., \& Ali, M. S. (2015). Factors affecting savings habits within millennials in Malaysia: Case study on students of Taylor's University. Paper presented at the Conference on Global Business, Economics, Finance and Social Sciences.

Ariffin, M. R., Sulong, Z., \& Abdullah, A. (2017). Students' Perception towards Financial Literacy and Saving Behavior. World Applied Sciences Journal, 35(10), 2194-2201.

Bandura, A. (1977). Self-efficacy: toward a unifying theory of behavioral change Psychological review, 84(2), 191. Bandura, A. (1989). Human agency in social cognitive theory. 44(9), 1175. American psychologist, 44(9), 1175.

Bandura, A. (2005). The evolution of social cognitive theory. Great minds in management, 9-35.

Batty, M., Collins, J. M., \& Odders-White, E. (2015). Experimental evidence on the effects of financial education on elementary school students' knowledge, behavior, and attitudes. Journal of Consumer Affairs, 49(1), 6996.

Bernheim, B. D., Ray, D., \& Yeltekin, S. (2015). Poverty and Self-Control. Econometrica 83(5), 1877-1911.

Biljanovska, N., \& Palligkinis, S. (2018). Control thyself: Self-control failure and household wealth. Journal of Banking \& Finance, 92, 280-294. 
Bowen, C. F. (2002). Financial knowledge of teens and their parents. Financial counseling and planning, 13(2), 93102.

Brown, S., \& Taylor, K. (2016). Early influences on saving behaviour: Analysis of British panel data. Journal of banking \& finance, 62, 1-14.

Bucciol, A., \& Veronesi, M. (2014). Teaching children to save: What is the best strategy for lifetime savings? . Journal of Economic Psychology,, 45, 1-17.

Chaulagain, R. P. (2019). Financial Literacy and Behavior of Small Borrowers in Nepal.

Choi, J. J., Laibson, D., \& Madrian, B. C. (2011). \$100 bills on the sidewalk: Suboptimal investment in 401 (k) plans Review of Economics and statistics, 93(3), 748-763.

Chowa, G. A., \& Despard, M. R. (2014). The influence of parental financial socialization on youth's financial behavior: Evidence from Ghana. Journal of Family and Economic Issues, 35(3), 376-389.

Cronqvist, H., \& Siegel, S. (2015). The origins of savings behavior. Journal of political Economy, 123(1), 123-169.

Dangol, J., \& Maharjan, S. (2018). Parental and Peer Influence on the Saving Behavior of the Youth. International Research Journal of Management Science, 3, 42-63.

De Ridder, D. T., Lensvelt-Mulders, G., Finkenauer, C., Stok, F., \& Baumeister, R. (2012). Taking stock of selfcontrol: A meta-analysis of how trait self-control relates to a wide range of behaviors Personality and Social Psychology Review,, 16(1), 76-99.

Deaton, A. (2005). Measuring poverty in a growing world (or measuring growth in a poor world) Review of Economics and statistics, 87(1), 1-19.

Denton, F., Fretz, D., \& Spencer, B. (2011). Independence and Economic Security in Old Age Toronto: UBC Press.

Dinc, M. S., \& Budic, S. (2016). The impact of personal attitude, subjective norm, and perceived behavioural control on entrepreneurial intentions of women. Eurasian Journal of Business and Economics, 9(17), 23-35.

Duflo, E., \& Saez, E. (2002). Participation and investment decisions in a retirement plan: The influence of colleagues' choices. 85(1), 121-148. Journal of public Economics, 85(1), 121-148.

Elias, S., \& Worku, A. (2015). Causal relationship between gross domestic saving and economic growth in east Africa: evidence from Ethiopia, Uganda and Kenya. Journal of Agriculture and Social Research (JASR), 15(2), 31-39.

Eun, B. (2019). Adopting a stance: Bandura and Vygotsky on professional development. Research in Education, 105(74-88).

Fang, W. T., Ng, E., Wang, C. M., \& Hsu, M. L. (2017). Normative beliefs, attitudes, and social norms: People reduce waste as an index of social relationships when spending leisure time. Sustainability, 9(10), 1696.

Firmansyah, D. (2014). The Influence of Family Backgrounds toward Student Saving Behavior: A Survey of College Students in Jabodetabek. International Journal of Scientific and Research Publication, 4(1), 1-6.

Franzoi, S. L. (2006). Social psychology (4th ed ed.). New York: McGraw-Hill.

Fujita, K., \& Han, H. A. (2009). Moving beyond deliberative control of impulses: The effect of construal levels on evaluative associations in self-control conflicts Psychological Science, 20(7), 799-804.

Gathergood, J. (2012). Self-control, financial literacy and consumer over-indebtedness. Journal of Economic Psychology, 33(3), 590-602.

Hanachi, P. (2005). Development of a questionnaire for assessing factors predicting blood donation among university students: a pilot study.

Herawati, N. T., Candiasa, I. M., Yadnyana, I. K., \& Suharsono, N. (2018). Factors That Influence Financial Behavior among Accounting Students in Bali. International Journal of Business Administration, 9(3), 30-38.

Hira, T. K. (1997). Financial attitudes, beliefs and behaviors: Differences by age. Journal of Consumer Studies and Home Economics, 21, 271-290.

Homan, A. M. (2016). The influence of parental financial teaching on saving and borrowing behavior. University of Groningen. 
Jamal, A. A. A., Ramlan, W. K., Karim, M. A., \& Osman, Z. (2015). The effects of social influence and financial literacy on savings behavior: A study on students of higher learning institutions in Kota Kinabalu, Sabah. International Journal of Business and Social Science, 6(11), 110-119.

Kampumure, A. C. (2015). Social Capital, Networks, and Knowledge Transfer The Academy of Management Review, 30(1), 146-165.

Karlan, D., Ratan, A. L., \& Zinman, J. (2014). Savings by and for the Poor: A Research Review and Agenda. Review of Income and Wealth, 60(1), 36-78.

Kast, F., Meier, S., \& Pomeranz, D. (2018). Saving more in groups: Field experimental evidence from Chile Journal of Development Economics, 133, 275-294.

Khatun, M. (2018). Effect of Financial Literacy and Parental Socialization on Students Savings Behavior of Bangladesh. International Journal of Scientific and Research Publications (IJSRP), 8. doi: 10.29322/IJSRP.8.12.2018.p8440

Kim, G. J., \& Hanna, S. D. (2017). Do Self-Control Measures Affect Saving Behavior?

Kim, J., Eys, M., Robertson-Wilson, J., Dunn, E., \& Rellinger, K. (2019). Subjective norms matter for physical activity intentions more than previously thought: Reconsidering measurement and analytical approaches. Psychology of Sport and Exercise, 43, 359-367.

Kim, J. H., \& Park, E. Y. (2015). Mediating effect of self-control in relation to depression, stress, and activities of daily living in community residents with stroke. Journal of physical therapy science, 27(8), 2585-2589.

Ky, S., Rugemintwari, C., \& Sauviat, A. (2018). Does mobile money affect saving behavior? Evidence from a developing country. Journal of African Economies, 27(3), 285-320.

Laible, D. J., Carlo, G., \& Roesch, S. C. (2004). Pathways to self-esteem in late adolescence: The role of parent and peer attachment, empathy, and social behaviors. Journal of adolescence, 27(6), 703-716.

Langevang, T., Namatovu, R., \& Dawa, S. (2012). Beyond necessity and opportunity entrepreneurship: motivations and aspirations of young entrepreneurs in Uganda. International Development Planning Review, 34(4), 439-460.

Lim, C. S. (2011). The analysis of psychological factors affecting savers in Malaysia.

Lindner, C., Nagy, G., \& Retelsdorf, J. (2015). The dimensionality of the Brief Self-Control Scale-an evaluation of unidimensional and multidimensional applications. Personality and Individual Differences, 86, 465-473.

Liu, F. (2014). Professional financial advice, self-control and saving behavior (Doctrate), The Ohio State University.

Liu, F., Yilmazer, T., Loibl, C., \& Montalto, C. (2019). Professional financial advice, self-control and saving behavior International Journal of Consumer Studies, 43(1), 23-34.

Lown, J., Kim, J., Gutter, M., \& Hunt, A. (2015). Self-efficacy and savings among middle and low income households. Journal of Family and Economic Issues, 36(4), 491-502.

Lyons, A. C. (2007). Credit practices and financial education needs of Midwest college students. Networks Financial Institute Working Paper((2007-WP)), 23.

Mangleburg, T. F., Doney, P. M., \& Bristol, T. (2004). Shopping with friends and teens' susceptibility to peer influence. Journal of retailing, 80(2), 101-116.

Martinsson, P., Myrseth, K. O. R., \& Wollbrant, C. (2014). Social dilemmas: When self-control benefits cooperation. Journal of Economic Psychology, 45, 213-236.

Mobarake, R. K., Juhari, R., Yaacob, S. N., \& Esmaeili, N. S. (2017). The moderating role of self-control in the relationship between peer affiliation and adolescents antisocial behavior in tehran, iran Asian Social Science, 10(9), 71.

Mozahem, N. A. (2020). Social cognitive theory and women's career choices: an agent-based model simulation. Computational and Mathematical Organization Theory, 1-26.

Nepomuceno, M. V., \& Laroche, M. (2017). When materialists intend to resist consumption: The moderating role of self-control and long-term orientation Journal of Business Ethics, 143(3), 467-483. 
Ningsih, R. S., Widiyanto, W., \& Sudarma, K. (2018). The Effect of Family Environment and School Environment Towards Savings Behavior Through Self Control in High School Students in Purwodadi City, Grobogan Regency. Journal of Economic Education, 7(1), 52-59.

Noor Zaihan, D. (2016). Determinants of saving behavior among generation Y students in Universiti Utara Malaysia (PhD), Universiti Utara Malaysia.

Norvilitis, J. M., \& MacLean, M. G. (2010). The role of parents in college students' financial behaviors and attitudes. Journal of Economic Psychology, 31(1), 55-63.

Rha, J. Y., Montalto, C. P., \& Hanna, S. D. (2006). The effect of self-control mechanisms on household saving behavior Journal of Financial Counseling and Planning, 17(2).

Sam, Y., Geetha, C., \& Mohidin, R. (2012). What were the factors that influence financial management behavior of undergraduates?. International Journal of Business Trends and Technology, 2(1), 2249-0183.

Shim, S., Barber, B. L., Card, N. A., Xiao, J. J., \& Serido, J. (2010). Financial socialization of first-year college students: The roles of parents, work, and education. Journal of Youth and Adolescence, 39(12), 1457-1470.

Sirine, H., \& Utami, D. S. (2016). Faktor-faktor yang memengaruhi perilaku menabung di kalangan mahasiswa Jurnal Ekonomi dan bisnis, 19(1), 27-52.

Strömbäck, C., Lind, T., Skagerlund, K., Västfjäll, D., \& Tinghög, G. (2017). Does self-control predict financial behavior and financial well-being? . Journal of Behavioral and Experimental Finance, 14, 30-38.

Taber, K. S. (2018). The use of Cronbach's alpha when developing and reporting research instruments in science education Research in Science Education, 48(6), 1273-1296.

Topa, G., Hernández, M., \& Zappalà, S. (2018). Financial Management behavior among young adults: The role of Need for Cognitive Closure in a three-wave moderated mediation model. Frontiers in Psychology, 9 , 2419.

Trzcińska, A., Sekścińska, K., \& Maison, D. (2018). The role of self-control and regulatory foci in money-saving behaviours among children Current Psychology, 1-11.

Vitell, S. J., Bing, M. N., Davison, H. K., Ammeter, A. P., Garner, B. L., \& Novicevic, M. M. (2009). Religiosity and moral identity: The mediating role of self-control Journal of Business Ethics, 88(4), 601-613.

Webley, P., \& Nyhus, E. K. (2006). Parents' influence on children's future orientation and saving.Journal of Economic Psychology, 27(1), 140-164.

Wills, T. A., Ainette, M., \& Walker, C. (2015). The Construct of Social Influence Department of Epidemiology and Population Health. Albert Einstein College of Medicine.

World Bank. (2017). World Bank End Extreme Poverty: Boost Shared Prosperity. Washington, DC. 